\title{
Insulin, glucagon, and somatostatin release from the prediabetic Chinese hamster
}

\author{
B. J. Frankel ${ }^{1}$, A. M. Heldt ${ }^{1}$, G. C. Gerritsen ${ }^{3}$ and G. M. Grodsky ${ }^{1,2}$ \\ ${ }^{1}$ Metabolic Research Unit and ${ }^{2}$ Department of Biochemistry and Biophysics, University of California, San Francisco, California and \\ ${ }^{3}$ Diabetes Research, The Upjohn Company, Kalamazoo, Michigan, USA
}

\begin{abstract}
Summary. Diabetes mellitus in the adult Chinese hamster is characterized by subnormal pancreatic insulin release in vitro, decreased insulin content, and lack of obesity. The cause of the islet B-cell failure is not clear. We measured insulin, glucagon, and somatostatin release from in vitro perfused pancreases of young (mean age 10 and 20 weeks), genetically diabetic animals (subline AC, mean plasma glucose 8.0 and $16.6 \mathrm{mmol} / 1$, respectively). Compared to age- and sexmatched normal hamsters (subline $\mathrm{M}$, mean plasma glucose $5.3 \mathrm{mmol} / \mathrm{l}$ ), the younger diabetic animals had a significantly elevated mean plasma glucose level, but net in vitro pancreatic release of insulin, glucagon, and somatostatin was normal. Pancreatic content of insulin and glucagon was also not significantly different from normal. At age 20 weeks, when the plasma glucose of the diabetic animals was even more elevated, pancreatic content and release of insulin were significantly
\end{abstract}

subnormal, whereas glucagon and somatostatin release were normal, and pancreatic content of glucagon was normal. In a similar group of young (mean age 10 weeks) diabetic animals, non-fasting plasma insulin levels were within the normal range, but the corresponding glucose levels were excessive in most of the animals (13 out of 19). In conclusion, 10-week-old diabetic hamsters show mild hyperglycaemia which cannot be accounted for directly by decreased pancreatic release in response to a glucose plus arginine stimulus in vitro. Decreased ability of the B cell to respond in vivo to hyperglycaemia or peripheral resistance to insulin may contribute to later B-cell failure in the older diabetic hamster.

Key words: Chinese hamster, diabetes mellitus, diabetes model, glucagon secretion, insulin resistance, insulin secretion, prediabetes, somatostatin secretion.
In the genetically diabetic Chinese hamster, overt diabetes is characterized by subnormal plasma insulin level [1], subnormal pancreatic insulin content [2-4], and subnormal glucose-stimulated insulin release [5-7]. Obvious obesity is never seen. However, because high plasma insulin levels [8-10] and hyperphagia [11] have been reported in some young Chinese hamsters before the onset of severe glycosuria, it is possible that they experience a transient, B-cell-exhausting period of insulin resistance and excessive insulin release. To detect any early abnormalities in islet hormone release, we measured insulin, glucagon, and somatostatin release from the pancreases of young, genetically diabetic (subline AC) and normal (subline $M$ ) Chinese hamsters aged 10 and 20 weeks. These in vitro results were compared with plasma insulin and glucose levels in non-fasted, 10 -week-old diabetic and normal animals.

\section{Materials and methods}

\section{Animals}

Male, genetically diabetic (subline AC) and normal (subline M) Chinese hamsters [7, 12] were obtained from the Upjohn Company colony at Kalamazoo, Michigan, USA. Both sublines had been inbred for 21-24 generations. Subline AC diabetic animals begin to show glycosuria at approximately 7 weeks of age. The youngest hamsters whose pancreas we can consistently perfuse are $6-10$ weeks old. Therefore animals aged 6-12 and 17-21 weeks were taken for perfusion (mean age 10 and 20 weeks). Animals were fed Ralston Purina mouse chow No. 5015 (St. Louis, Missouri, USA) and water ad libitum. Animals were housed in a temperature- and light-controlled room (light on $06.00-18.00 \mathrm{~h}$ ).

\section{Procedures}

Blood was drawn from the orbital sinus [13] from non-fasted animals, usually between 10.30 and $11.00 \mathrm{~h}$, and plasma glucose was determined with a glucose analyzer (Beckman, Fullerton, California, USA). For each animal, single glucose measurements were performed $0-3$ days before perfusion. Because plasma insulin levels have not been well characterized in subline $\mathrm{AC}$ diabetic animals at the apparently critical 10 -week-old stage, we measured non-fasting plasma insulin and glucose levels in 18-19 male and female diabetic and normal hamsters. This reference group of young animals was agematched (age range 6-12 weeks, mean age 9.6 weeks) with the younger diabetic hamsters from which pancreases were perfused. Pancreas perfusion was performed on non-fasted animals as described previously [5], except that the total perfusion flow rate was $1.0 \mathrm{ml} / \mathrm{min}$. Also, $1 \%$ human serum albumin (Armour Pharmaceuticals, Kankakee, Illinois) and 3\% Dextran T-40 (Pharmacia, Piscataway, New Jersey) were used instead of $4 \%$ albumin [14]. The combined glucose plus arginine was injected by sidearm syringe (Infusion pump, Model 903, Harvard Apparatus, Millis, Massachusetts, USA) 
Table 1. Development of diabetes in the Chinese hamster

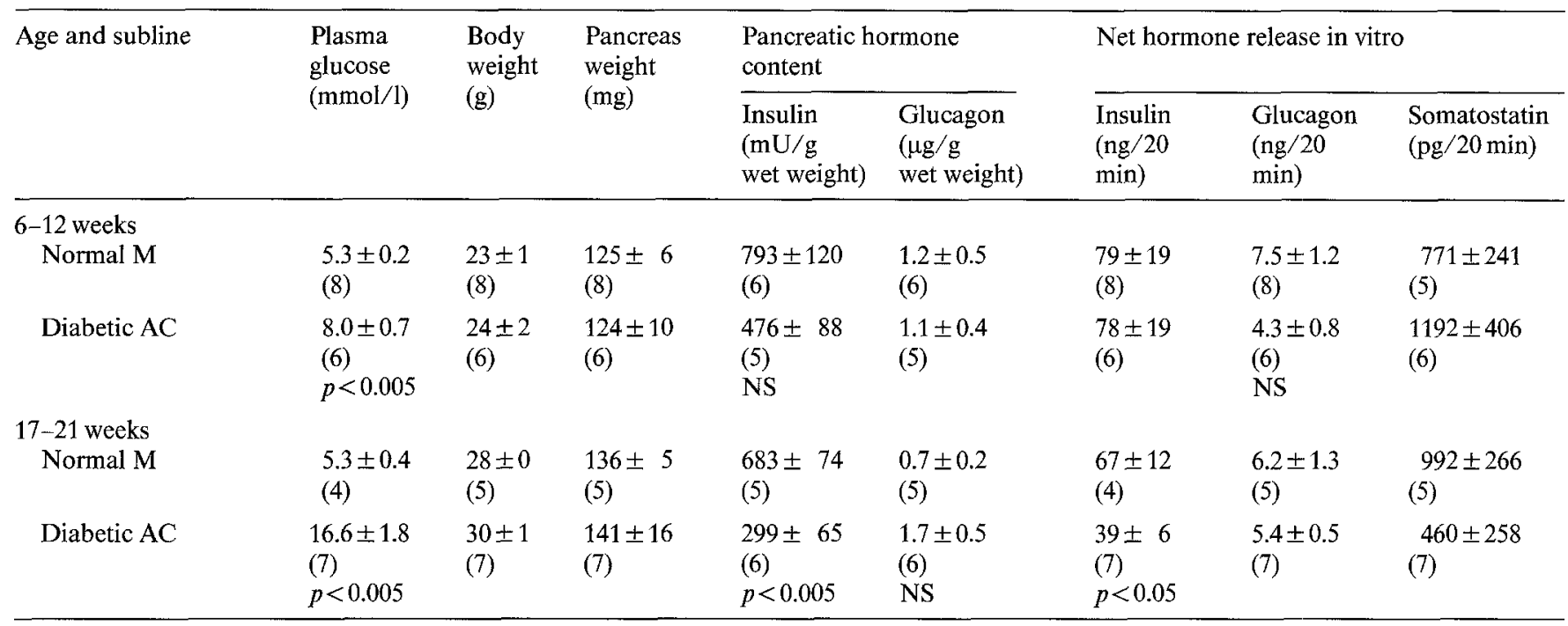

Data are given as mean \pm SEM; number of animals in parentheses; hormone contents are expressed per $g$ wet weight of pancreas

at $0.05 \mathrm{ml} / \mathrm{min}$ to deliver a final concentration of glucose $(5.6 \mathrm{mmol} / \mathrm{l})$ and arginine $(20 \mathrm{mmol} / \mathrm{l})$. After perfusion, pancreases were dissected free from other tissues, rinsed, blotted, weighed, and frozen until extraction in acid-ethanol-Benzamidine for insulin and glucagon content [15]. Immunoreactive insulin was measured by a solid-phase, single-antibody radioimmunoassay [16] using pork insulin as standard [5]. Immunoreactive glucagon was measured by a dextran-charcoal method, modified [17] from Unger and Eisentraut [18], using Unger $30 \mathrm{~K}$ or Unger $04 \mathrm{~A}$ antiserum. These two antisera gave identical results in our assays of glucagon release from the perfused normal rat pancreas in vitro. Somatostatin was measured by a double-antibody radioimmunoassay using Vale's S201 antiserum [19]. Net hormone release was calculated as the 'area under the curve' with subtraction of a constant baseline (mean of hormone release at $\min -2,-1$ and 0 ) for insulin and somatostatin or subtraction of a declining baseline (straight line from $\min 1$ [mean of $\min -2,-1,0]$ to min 20 [mean of $\min 25,28,30]$ ) for glucagon.

\section{Statistical analysis}

Statistical differences were determined by two-tailed Student's t-test. Plasma glucose levels were compared with other parameters by linear correlation. Results are expressed as mean \pm SEM.

\section{Results}

Mean plasma glucose, body weight, pancreas weight, pancreatic content of insulin, glucagon and net hormone release from the normal and diabetic Chinese hamsters at age 6-12 weeks (mean 10) and 17-21 weeks (mean 20) are shown in Table 1. In the younger diabetic animals, only plasma glucose was significantly elevated over the non-diabetic, age-matched controls. Mean pancreatic insulin content was $59 \%$ of the normal level, but this difference was not statistically significant. The pancreatic insulin content was negatively correlated with the plasma glucose level $(r=-0.831, n=5, p<$ 0.05 ). By age 20 weeks, mean plasma glucose level had approximately doubled and insulin content and insulin release were significantly subnormal $(p<0.005$ and $p$
0.05 , respectively). Plasma glucose was correlated only with glucagon content ( $r=0.791, n=6, p<0.05$ in diabetic animals).

The patterns of insulin, glucagon, and somatostatin release in response to glucose plus arginine from the in vitro perfused pancreases of these animals are shown in Figure 1. Basal release of insulin, glucagon, and somatostatin (mean of $\min -5$ to 0 ) was normal at each age. Basal release of insulin was constant, whereas glucagon and somatostatin declined gradually, a characteristic previously observed for glucagon and related to surgical stress to the pancreas [20]. In the normal animals, glucose plus arginine-stimulated insulin release was biphasic (first spike at 6 or $7 \mathrm{~min}$ ), while glucagon secretion was rapid and followed by a waning period as observed previously [15]. Somatostatin secretion gradually increased during the stimulatory period and was sustained during the 10 -min observation period after stopping the stimulus. In the younger diabetic animals, insulin release was not significantly different from normal, while at 20 weeks the diabetic hamsters showed significantly subnormal insulin secretion, which is characteristic of other adult diabetic sublines [15, 21].

Simultaneous non-fasting plasma insulin and glucose levels were measured in a reference group of 6-12-week-old diabetic and normal hamsters (Table 2). The mean glucose level $(12.4 \pm 1.6 \mathrm{mmol} / \mathrm{l})$ was not significantly different from the mean plasma glucose of the animals from which pancreases were perfused $(8.0 \pm 0.7 \mathrm{mmol} / 1, p \cong 0.15)$. Plasma insulin levels in the diabetic animals fell within the range for the normal hamsters, but the corresponding glucose levels were excessive ( $>3$ SD above the mean of the normal animals) in 13 out of 19 cases. When expressed as an insulin-toglucose ratio for each animal, 18 of the 19 diabetic animals fell below the mean insulin-to-glucose ratio for normal hamsters (data not shown). 



Fig. 1. Insulin, glucagon and somatostatin release in response to glucose $(5.6 \mathrm{mmol} / \mathrm{l})$ plus arginine $(20 \mathrm{mmol} / \mathrm{l})$ from the pancreases of normal $(-)$ and diabetic $(O---O)$ Chinese hamsters at 6-12 and 17-21 weeks of age. Data are given as mean \pm SEM for the number of animals shown. ${ }^{*} p<0.05$

\section{Discussion}

In the present study, 10-week-old diabetic animals showed hyperglycaemia in the presence of normal plasma insulin levels and normal in vitro pancreatic insulin release. These data suggest a decreased ability of the $B$ cells in diabetic hamsters to respond in vivo to hyperglycaemia. Perhaps some humoral factor blocks in- creased insulin release in vivo. Alternatively, the tendency (not-statistically-significant, $p \cong 0.07$ ) toward decreased pancreatic insulin content suggests that decreased pancreatic insulin synthesis or storage is responsible for the decreased insulin release. Peripheral resistance to insulin is suggested by the excessive plasma glucose levels in the presence of normal plasma insulin levels. 
Table 2. Plasma insulin and glucose levels in 6-12-week-old hamsters

\begin{tabular}{|c|c|c|c|}
\hline Subline & $\begin{array}{l}\text { Plasma } \\
\text { insulin } \\
(\mathrm{mU} / \mathrm{l})\end{array}$ & $\begin{array}{l}\text { Plasma } \\
\text { glucose } \\
(\mathrm{mmol} / \mathrm{l})\end{array}$ & $\begin{array}{l}\text { Insulin/glucose } \\
\text { ratio }\end{array}$ \\
\hline $\begin{array}{l}\text { Normal M } \\
\quad(n=18)\end{array}$ & $\begin{array}{l}108 \pm 13 \\
(12-223)\end{array}$ & $\begin{array}{c}4.9 \pm 0.2 \\
(3.6-5.8)\end{array}$ & $\begin{array}{l}21.8 \pm 2.8 \\
(3.1-49.6)\end{array}$ \\
\hline $\begin{array}{c}\text { Diabetic AC } \\
(n=19)\end{array}$ & $\begin{array}{l}110 \pm 11 \\
(44-228)\end{array}$ & $\begin{array}{l}12.4 \pm 1.6^{\mathrm{a}} \\
(4.9-27.9)\end{array}$ & $\begin{array}{l}11.7 \pm 1.5^{b} \\
(2.0-23.2)\end{array}$ \\
\hline
\end{tabular}

Data are given as mean \pm SEM with the range in parentheses. ${ }^{\mathrm{a}} p<0.001 ;{ }^{\mathrm{b}} p<0.005$

In the present study, we found no evidence of excessive pancreatic insulin release in vitro as is seen in the $\mathrm{db} / \mathrm{db}$ mouse [22] or as suggested by the hyperinsulinaemia seen in 2-week-old prediabetic hamsters [9]. Possibly 10 weeks is too late to see any excessive insulin secretion, and the fall in pancreatic insulin content is the earliest manifestation of B-cell exhaustion and precedes any observable defect in insulin release in vitro.

To detect possible defects in both insulin and glucagon release, we used a 'low' glucose $(5.6 \mathrm{mmol} / 1)$ plus 'high' arginine $(20 \mathrm{mmol} / \mathrm{l})$ combination. A 'high' glucose challenge might have uncovered a defect in vitro in the younger diabetic animals' response, which is specific to glucose.

The diabetic pancreases showed normal glucagon content and release at age 10 and 20 weeks. Older ACsubline diabetic hamsters showed clearly elevated pancreatic glucagon levels and somewhat elevated plasma glucagon levels [7]. Excessive glucagon release from the perfused pancreas in vitro is a characteristic in some, but not all, diabetic sublines [23] and from the present data, the excessive glucagon release appears to develop later than the insulin secretory defect.

The combination of glucose plus arginine caused a slowly increasing release of somatostatin (with no first phase) in both normal and diabetic pancreases. After stopping the stimulus, somatostatin release did not return to baseline within $10 \mathrm{~min}$ as insulin and glucagon release usually do. In fact, somatostatin release showed an overshoot or "off response" in some cases. Since somtatostatin release was not significantly different in the normal and diabetic pancreases, it seems unlikely that somatostatin plays a primary role in the early diabetes of AC subline of Chinese hamsters.

Obesity, insulin resistance, and excessive insulin secretion precede B-cell exhaustion and subnormal insulin release in C57BLKsJ $d b / d b$ mice [22]. In those mice, restriction of food intake at an early age partially prevented the obesity, postponed the pancreatic B-cell impairment, and postponed the early death characteristic of the animals [ 24 and $O$. Berglund, personal communication]. Similarly, restriction of food intake in prediabetic Chinese hamsters for 150 days reduce the severity of subsequent glycosuria and ketonuria [25]. Therefore, early hyperphagia may contribute to later insulin resistance and pancreatic impairment.
In a previous study we treated prediabetic Chinese hamsters with exogenous insulin by continuous infusion in vivo for 1 month [21]. The insulin dosage was sufficient to increase blood insulin levels but did not cause significant lowering of plasma glucose. However, the insulin-treated prediabetics gained slightly more weight and later developed more severe glycosuria than their saline-treated prediabetic siblings. These results suggest that increased circulating insulin promotes insulin resistance and contributes to later pancreatic exhaustion, possibly by increasing body weight (primarily fat) [25] and decreasing insulin receptors.

In conclusion, the present study shows that pancreatic insulin, glucagon, and somatostatin release in vitro are normal in the young diabetic (subline AC) Chinese hamster. Early hyperglycaemia in the presence of "normal" plasma insulin levels and a tendency toward decreased pancreatic insulin levels suggest that the diabetic B cell may begin to fail before the age of 10 weeks with no "hyperinsulin" secretion observable in vitro at age 10 or 20 weeks. Abnormalities in glucagon and somatostatin release do not appear in 10 - or 20 -week-old subline AC diabetic hamsters. These data do not rule out the possibility that non-islet factors may contribute to insulin resistance and later B-cell failure.

Acknowledgments. We are indebted to M. Gishizky, M.A. Jones, and M. Manning for their technical assistance. We thank W.Vale for providing the somatostatin antiserum, S-201, J.Rivier for synthesizing and providing [Tyr-Ala']-SS, used after iodination in the somatostatin assay, R. Unger for glucagon antiserum, and the Armour Pharmaceutical Company for albumin. This work was supported in part by NIH grants AM 26033, AM21933 and 01410, the Swedish Medical Research Council (project no.06813), the Syskonen Svenssons Fund for Medical Research, the Swedish Diabetes Association, and the Clas Groschinsky Memorial Fund.

\section{References}

1. Gerritsen GC, Blanks MC (1974) Characterization of Chinese hamsters by metabolic balance, glucose tolerance, and insulin secretion. Diabetologia 10 (Suppl): 493-500

2. Gerritsen GC, Dulin WE (1967) Characterization of diabetes in the Chinese hamster. Diabetologia 3: 74-84

3. Sims EAH, Landau BR (1967) Diabetes mellitus in the Chinese hamster. I. Metabolic and morphologic studies. Diabetologia 3: 115-123

4. Grodsky GM, Frankel BJ, Gerich JE, Gerritsen GC (1974) The diabetic Chinese hamster: in vitro insulin and glucagon release; the "chemical diabetic"; and the effect of diet on ketonuria. Diabetologia 10 (Suppl): 521-528

5. Frankel BJ, Gerich JE, Hagura R, Fanska RE, Gerritsen GC, Grodsky GM (1974) Abnormal secretion of insulin and glucagon by the in vitro perfused pancreas of the genetically diabetic Chinese hamster. J Clin Invest 53: 1637-1646

6. Grodsky GM, Frankel BJ (1982) Diabetes mellitus in the Chinese hamster. In: Martin JM, Holland FJ (eds) The etiology and pathogenesis of insulin-dependent diabetes. Advances in Pediatric Research Series, Raven Press, New York, pp 239-249

7. Gerritsen GC (1982) The Chinese hamster as a model for the study of diabetes mellitus. Diabetes 31 (Suppl 1): 14-21

8. Gerritsen GC, Blanks MC (1979) Effect of diet limitation on development of diabetes in non-hyperglycemic prediabetic Chinese 
hamsters. In: Camerini-Davalos R, Hanover B (eds) Treatment of early diabetes. Academic Press, New York, Adv Exptl Med Biol 119: 237-242

9. Gerritsen GC, Connell MA, Blanks MC (1981) Effect of environmental factors including nutrition on genetically determined diabetes of Chinese hamsters. Proc Nutr Soc 40: 237-245

10. Renold AE, Cameron DP, Amherdt M, Stauffacher W, Marliss E, Orci L, Rouiller C (1972) Endocrine-metabolic anomalies in rodents with hyperglycemic syndromes of hereditary and/or environmental origin. Isr J Med Sci 8: 189-206

11. Gerritsen GC, Blanks MC (1970) Preliminary studies on food and water consumption of prediabetic Chinese hamsters. Diabetologia 6: $177-179$

12. Dublin WE, Gerritsen GC, Chang AY (1982) Experimental and spontaneous diabetes in animals. In: Ellenberg M, Rifkin $\mathrm{H}$ (eds) Diabetes mellitus: theory and practice, 3rd edn. Medical Examination Publishing Company, Garden City, New York, pp 361-408

13. Riley V (1960) Adaptation of orbital bleeding technic to rapid serial blood studies. Proc Soc Exp Biol Med 104: 751-754

14. Grodsky GM, Fanska RE (1975) The in vitro perfused pancreas. In: Hardman JG, O'Malley BW (eds) Methods in enzymology, vol 39. Academic Press, New York, pp 364-372

15. Frankel BJ, Gerich JE, Fanska RE, Gerritsen GC, Grodsky GM (1975) Responses to arginine of the perfused pancreas of the genetically diabetic Chinese hamster. Diabetes 24: 272-279

16. Lundquist I, Fanska R, Grodsky GM (1976) Interaction of calcium and glucose on glucagon secretion. Endocrinology 99: 1304-1312

17. Gerich JE, Charles MA, Grodsky GM (1974) Characterization of the effects of arginine and glucose on glucagon and insulin release from the perfused rat pancreas. J Clin Invest 54: 833-841

18. Unger RH, Eisentraut AM (1967) Glucagon. In: Grey CH, Bacharach AL (eds) Hormones in blood, vol 1, 2nd ed. Academic Press, New York, pp 83-128
19. Vale W, Rivier J, Ling N, Brown M (1978) Biologic and immunologic activities and applications of somatostatin analogs. Metabolism 27 (Suppl 1): 1391-1401

20. Lundquist I, Fanska R, Grodsky GM (1976) Direct calcium-stimulated release of glucagon from the isolated perfused rat pancreas and the effect of chemical sympathectomy. Endocrinology 98: $815-818$

21. Frankel BJ, Grodsky GM (1979) Effect of low-dose insulin treatment on subsequent incidence of diabetes in genetically prediabetic Chinese hamsters. Diabetes 28: 544-547

22. Berglund O, Frankel BJ, Hellman B (1978) Development of the insulin secretory defect in genetically diabetic $(d b / d b)$ mouse. Acta Endocrinol. 87: 543-551

23. Frankel BJ, Heldt AM, Grodsky GM (1982) Insulin and glucagon in the diabetic Chinese hamster. Differences among inbred sublines. Diabetologia 22: 292-295

24. Cox JE, Powley TL (1977) Development of obesity in diabetic mice pair-fed with lean siblings. J Comp Physiol Psychol 91: 347-358

25. Gerritsen GC, Blanks MC, Miller RL, Dulin WE (1974) Effect of diet limitation on the development of diabetes in prediabetic Chinese hamsters. Diabetologia 10: 559-566

Received: 16 March 1983

and in revised form: 18 June 1984

Dr. B. J. Frankel

Department of Histology and Cell Biology

University of Umeå

S-901 87 Umeå

Sweden 